\title{
Decadal Prediction Skill of BCC-CSM1.1 with Different Initialization Strategies
}

\author{
Xiaoge XIN \\ Laboratory for Climate Studies, National Climate Center, China Meteorological Administration, China
}

Min WEI

National Meteorological Information Center, China Meteorological Administration, China

Ministry of Education Key Laboratory for Earth System Modeling, Department of Earth System Science, and Joint Center for Global Change Studies (JCGCS), Tsinghua University, China

\section{Qingquan LI}

Laboratory for Climate Studies, National Climate Center, China Meteorological Administration, China Collaborative Innovation Center on Forecast and Evaluation of Meteorological Disasters, Nanjing University of Information Science and Technology, China

\section{Wei ZHOU}

State Key Laboratory of Tropical Oceanography, South China Sea Institute of Oceanology, Chinese Academy of Sciences, China

\section{Yong LUO and Zongci ZHAO}

Ministry of Education Key Laboratory for Earth System Modeling, Department of Earth System Science, and Joint Center for Global Change Studies (JCGCS), Tsinghua University, China

(Manuscript received 19 July 2018, in final form 18 March 2019)

\begin{abstract}
Two sets of decadal prediction experiments were performed with Beijing Climate Center climate system model version 1.1 (BCC-CSM1.1) with different initialization strategies. One experiment is relaxing modeled ocean temperature to the Simple Ocean Data Assimilation (SODA) reanalysis data (SODAInit). In the other (EnOI_ HadInit) experiment, the modeled ocean temperature were relaxed toward the assimilated ocean data, which were generated by assimilating sea surface temperature (SST) of the Hadley Centre Sea Ice and Sea Surface Temperature (HadISST) data to the ocean model of BCC-CSM1.1 using Ensemble Optimum Interpolation (EnOI) method. Comparisons between EnOI_HadInit and SODAInit hindcasts show that EnOI_HadInit is more skillful in predicting SST over the North Pacific, the southern Indian Ocean, and the North Atlantic. Improved prediction skill is also found for surface air temperature (SAT) over South Europe, North Africa, and Greenland, which is associated with the skillful prediction of the Atlantic multi-decadal oscillation in EnOI HadInit. EnOI HadInit and SODAInit are both skillful in predicting East Asian SAT, which is related to their skillful predictions of the tropical western Pacific SST. The result indicates that assimilated data generated by the ocean model of BCC-CSM1.1
\end{abstract}

Corresponding author: Qingquan Li, Beijing Climate Center, Zhongguancun Nandajie No.46, Haidian District, Beijing, 100081, China

E-mail: liqq@cma.gov.cn

J-stage Advance Published Date: 1 April 2019

CThe Author(s) 2019. This is an open access article published by the Meteorological Society of Japan under a Creative Commons Attribution 4.0 International (CC BY 4.0) license (https://creativecommons.org/licenses/by/4.0). 
with EnOI assimilation provide better initial conditions than SODA reanalysis data for the decadal predictions of BCC-CSM1.1.

Keywords decadal prediction; initialization; Beijing Climate Center climate system model; Ensemble Optimum Interpolation

Citation Xin, X., M. Wei, Q. Li, W. Zhou, Y. Luo, and Z. Zhao, 2019: Decadal prediction skill of BCC-CSM1.1 with different initialization strategies. J. Meteor. Soc. Japan, 97, 733-744, doi:10.2151/jmsj.2019-043.

\section{Introduction}

Decadal climate predictions are of particular scientific interest in recent years, because of their potential impacts on economy and social development. Initial condition and external forcing are both important for decadal predictions with climate models (Smith et al. 2007; Keenlyside et al. 2008). The role of initialization was seen as a better representation of the internal variability. Initialized climate prediction is an important component of Coupled Model Intercomparison project phases 5 (CMIP5) (Taylor et al. 2012). Multi-model mean ensemble of CMIP5 showed that the enhancement in skill due to the initialization is robust for global mean temperature and the Atlantic multi-decadal oscillation (AMO) (IPCC 2013). Increased skill for sea surface temperature (SST) was found for some models in the North Atlantic, the Indian Ocean, and the North Pacific ( $\mathrm{Wu}$ and Zhou 2012; Doblas-Reyes et al. 2013; Ham et al. 2014). However, Beijing Climate Center climate system model version 1.1 (BCC-CSM1.1) for CMIP5 had poor decadal prediction skill in the North Pacific and the North Atlantic (Gao et al. 2012; Han et al. 2017), and needs further improvement.

The Pacific and Atlantic climate variability is an important driver of climate variability over the continents (e.g., Zhou et al. 2008; Si and Ding 2016). Skillful prediction arising from the initialization was found for surface air temperature (SAT) over America, northern Eurasia (Keenlyside et al. 2008; DoblasReyes et al. 2013), East Asia (Xin et al. 2018), and for precipitation in Africa (Gaetani and Mohino 2013). However, the decadal prediction skill was still poor. Improving the decadal predictions skill of climate models was considered to be a grand scientific challenge of CMIP6 (Eyring et al. 2016).

Skill of decadal climate prediction depends greatly on the accurate estimation of initial climate states. Modeling groups used different initialization tech- niques in decadal predictions of CMIP5 (Meehl et al. 2014). Most of the models used full-filed initialization to restore oceanic temperature to observation-based ocean reanalysis, including BCC-CSM1.1, CFSv22011, CMCC-CM, EC-Earth, FGOALS-s2, FGOALSg2, and HadCM3. There are also models restoring the modeled ocean temperature to the assimilated ocean data using offline assimilation in the ocean model (CanCM4, CNRM-CM5). Models including CCSM4, GFDL-CM2.1, and GEOS-5 used assimilation in the coupled prediction system. Due to the large computation cost of the coupled assimilation in decadal predictions, full-field initialization with reanalysis ocean data or assimilated ocean data are commonly used for climate models. Bellucci (2013) found a strong predictive skill dependency on the ocean data assimilation product used to constrain the oceanic initial conditions.

Our recent study assimilated the HadISST in the ocean model of BCC-CSM1.1 via the Ensemble Optimum Interpolation (EnOI) method, and generated better prediction skill in the North Atlantic than using Simple Ocean Data Assimilation (SODA) reanalysis in the initialization (Wei et al. 2017). The possible improvement for the prediction skill over the globe needs further investigation, especially for the SST in the Pacific and Indian oceans and SAT over the land. This is the main aim of this paper. Our results will provide reference for the initialization strategy adopted by BCC-CSM model in Decadal Climate Prediction Comparison (DCPP) of CMIP6 (Boer et al. 2016).

The paper is organized as follows. Data and methods used in this study are presented in Section 2. Global SST prediction skills are described in Section 3. Section 4 explores the prediction skills of SAT over the land. The conclusions of this paper are presented in Section 5. 


\section{Model, experiments, data and methodology}

\subsection{Model}

The model used in this study is BCC-CSM1.1 developed by Beijing Climate Center, which participated in CMIP5 and carried out most of the experiments (Xin et al. 2013). The atmospheric component of BCCCSM1.1 is BCC AGCM2.1 with T42 resolution (about $280 \mathrm{~km}$ ) in the horizontal and 26 vertical layers (Wu et al. 2010). The oceanic component is the Modular Ocean Model version 4 (MOM4) with the tripolar grid of $1^{\circ} \times 1 / 3^{\circ}$ horizontal resolution and 40 vertical levels, which is named MOM4_L40 (Griffies et al. 2005; Li et al. 2015). More detailed descriptions about BCC-CSM1.1 can be found in Wu et al. (2013).

\subsection{Experiments and data}

Two sets of decadal prediction experiments were carried out with BCC-CSM1.1. The experimental names, ocean initiation, and integration time are listed in Table 1. Each experiment consists of 45 hindcasts, initialized annually for the period of 1961-2005 and integrated for ten years. In both experiments, the modeled oceanic temperature is nudged to observationbased ocean data, with the restoring timescale of one day. The difference between these two experiments is the initialization strategy of the ocean condition. One experiment is to restore the modeled sea temperature to the SODA reanalysis data (Cartchion and Giese 2008), hereafter called SODAInit. The other experiment is to restore the modeled sea temperature to the EnOI-assimilated data (ASSIM), generated by assimilating the Hadley Centre Sea Ice and SST data set (HadISST) data (Rayner et al. 2003) to MOM4 L40 model using the EnOI method, hereafter called EnOI_HadInit.

In the EnOI assimilation, the background error covariance is kept unchanged throughout the assimilation cycle, which is estimated from a prescribed static ensemble. The procedure for the assimilation is as follows. First, a control simulation is run with the MOM4 L40 model forced by daily NCEP/NCAR reanalysis (Kalnay et al. 1996). This control run is used to generate the static ensembles. Then the EnOI method is used to assimilate the HadISST data to the MOM4 L40 model, with the time window of one month. The generated data is named ASSIM. As indicated in Wei et al. (2017), the ASSIM data are more coordinated with the ocean of BCC-CSM1.1 model than the SODA reanalysis.

The CMIP5 historical simulation of BCC-CSM1.1 with no initialization is also used for comparison (Xin et al. 2013), hereafter called NoInit (Table 1). All experiments including SODAInit, EnOI_HadInit, and NoInit were forced by the identical external forcing, including greenhouse gases, solar irradiation, volcanic activity, ozone, and aerosols. Each experiment consists of three ensemble members. The results shown in this study are the ensemble means.

\subsection{Data and methodology}

The observation data used to validate the prediction skill are as follows. The SAT data are from Global Historical Climatology Network-Climate Anomaly Monitoring System (GHCN-CAMS) dataset (Fan and van del Dool 2008). The precipitation data are from Climatic Research Unit Time-Series Version 3.23 (CRU-TS3.23) dataset (University of East Anglia Climatic Research Unit et al. 2015). The SST data are from the Extended Reconstructed Sea Surface Temperature (ERSST) Version 4 (ERSST V4) dataset (Huang et al. 2016).

The reason why we use ERSST in the validation is that this dataset is independent from the SODA data and HadISST data used in the initialization. In fact, the SST of ERSST is close to that of the HadISST (Fig. 1). The correlation coefficient between the global $\left(70^{\circ} \mathrm{S}-60^{\circ} \mathrm{N}\right)$ mean SST anomalies from 1960 to 2005 is 0.98. In the EnOI-assimilation, we use SST from the HadISST but not the SODA reanalysis. This may be unequal for the two sets of decadal prediction in this study. Therefore, we compare the interannual

Table 1. Experimental design for SODAInit, EnOI_HadInit and NoInit.

\begin{tabular}{llll}
\hline Experiment name & \multicolumn{1}{c}{ Ocean initialization } & \multicolumn{1}{c}{ Years } & Ensemble size \\
\hline SODAInit & $\begin{array}{l}\text { Full-field initialization. } \\
\text { Relaxing toward SODA reanalysis data. }\end{array}$ & $\begin{array}{l}\text { Annual forecasts for ten years, } \\
\text { staring at 1961, 1962, .., 2005 }\end{array}$ \\
\hline EnOI_HadInit & $\begin{array}{l}\text { Full-filed initialization. } \\
\text { Offline assimilation of HadISST with EnOI } \\
\text { method in the ocean model of BCC-CSM1.1. }\end{array}$ & $\begin{array}{l}\text { Annual forecasts for ten years, } \\
\text { staring at 1961, 1962, .., 2005 }\end{array}$ \\
\hline NoInit & No & $1850-2005$ & 3 \\
\hline
\end{tabular}




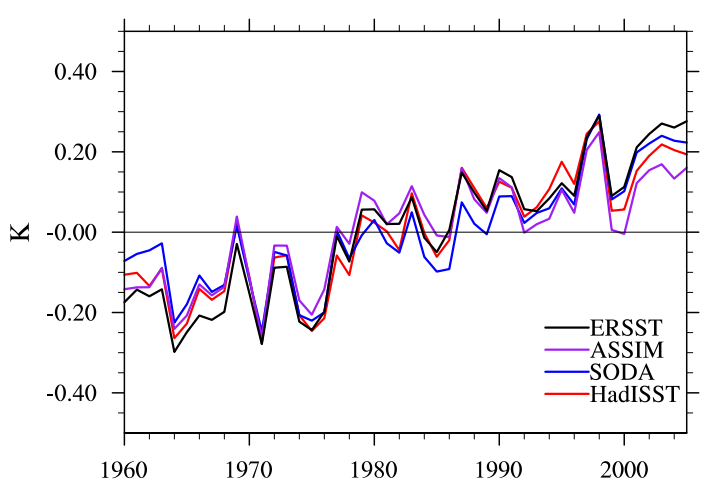

Fig. 1. Global annual mean SST anomalies (K) with respect to the 1960-2005 climatology for HadISST dataset, ERSST dataset, SODA reanalysis, and the EnOI-assimilated data (ASSIM) generated in this study.

anomalies of the global mean SST for the HadISST, ASSIM and SODA datasets. The time series from the three different datasets are similar (Fig. 1). The correlation coefficient between SODA and HadISST (ERSST) is 0.95. The SST from the ASSIM data also shows great resemblance with that from the HadISST and ERSST, with the correlation coefficients both at 0.96, indicating the effectiveness of the assimilation. We infer that the different SST dataset used in the assimilation may not introduce much difference for the interannual variability of the output data, since they are all observation-based data. However, the ASSIM data shows some difference from the SODA data, and the correlation coefficient between the global mean SST anomalies of the two datasets is 0.90 . This may be attributed to the different scheme and model version used in the assimilation processes.

Full-field initialization leads to initial shocks in decadal predictions (García-Serrano and Doblas-Reyes 2012), so we compare the anomalies in the analysis. For the NoInit and observed, anomalies are relative to their respective climatology. The anomalies of decadal predictions are defined with respect to the climatology of the ensemble mean and lead time, as used in earlier studies (García-Serrano and Doblas-Reyes 2012; Wei et al. 2017; Xin et al. 2018). We will focus on the 4-yr average forecast periods $(1-4,2-5,3-6,4-7,5-8$, 6-9) of the decadal hindcasts. A 4-yr running mean is also applied to the observed and NoInit anomalies in order to equivalently compare with the decadal hindcasts (García-Serrano and Doblas-Reyes 2012; Goddard et al. 2012; Kim et al. 2012; Gaetani and Mohino 2013).
Root-mean-square error (RMSE) and anomaly correlation coefficient (ACC) relative to the observations are two metrics we used to estimate the prediction skill of the decadal hindcasts. To study the role of the ocean initialization on the internal climate variability, the linear trend was removed in observation and simulation data at each grid before calculating ACC. In the student's $t$ test of ACC, the effective sample size $\left(N_{e}\right)$ was calculated after removing the auto-correlation (Bretherton et al. 1999).

$$
N_{e}=N\left(1-r_{1} r_{2}\right) /\left(1+r_{1} r_{2}\right),
$$

where $N$ is the sample size and $r_{1}$ and $r_{2}$ are the lag-1 autocorrelations of the two time series.

\section{Prediction skill of SST}

\subsection{SST over the globe}

The skill improvement due to the initialization is assessed by the ratio of the RMSEs between the decadal hindcast and NoInit for the forecast years of 2-5. As shown in Figs. 2a, b, both EnOI_HadInit and SODAIinit have less RMSE than the NoInit over the tropical western Pacific, North Pacific, and tropical Atlantic Ocean. The EnOI HadInit experiment shows a smaller RMSE ratio over tropical western Pacific, central North Pacific, Northeast Atlantic, and the southern Indian Ocean than the SODAInit (Fig. 2c), indicating a higher prediction skill for EnOI_HadInit. It is noted that there are larger RMSEs in the EnOI HadInit and SODAInit hindcasts than the NoInit over parts of the North Atlantic and Indian Oceans (Figs. $2 a, b)$, indicating that the error in the variance of the SST anomalies could hardly be reduced through the initialization in these regions. Such a phenomenon also appears in some other models, such as the FGOALS-S2 (Wu et al. 2015). The reason for this phenomenon may partly be related to the small number of the ensembles.

The detection of significant ACC after removing the linear trend suggests the predictive skill beyond the global warming signal. EnOI_HadInit (Fig. 3a) hindcast displays a significant ACC in the tropical western Pacific Ocean, North Pacific Ocean, southern Indian Ocean, and extratropics of the North Atlantic Ocean for the forecast years 2-5. While in the hindcast of SODAInit (Fig. 3b), significant ACC mainly exists in the tropical western Pacific Ocean and tropical Atlantic Ocean. The NoInit shows a significant ACC only in the tropical Atlantic Ocean (Fig. 3c). Consequently, it is concluded that the ocean initiation scheme of SODA mainly improves the prediction skill in the tropical western Pacific Ocean compared to no initialization 

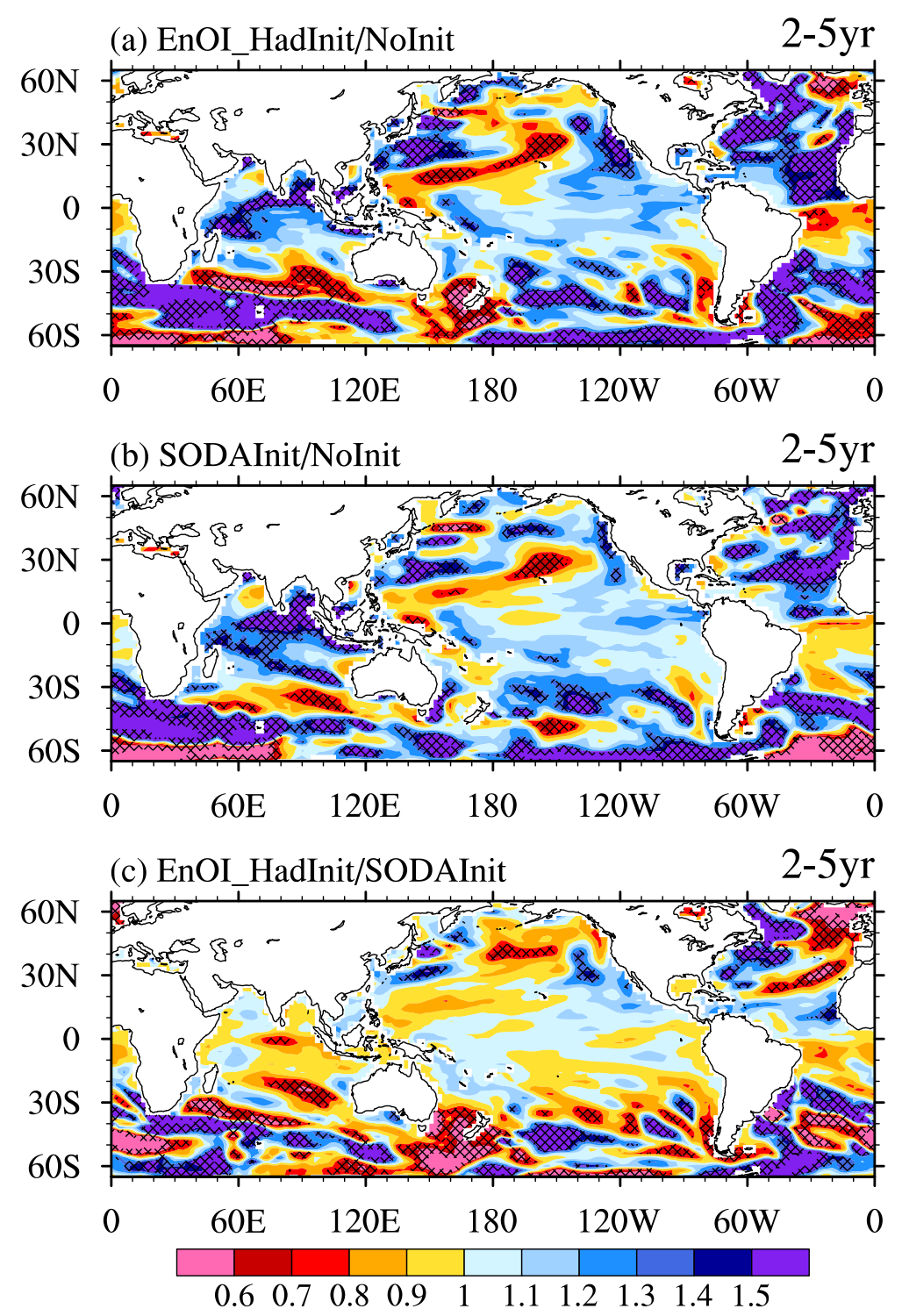

Fig. 2. Ratios of SST RMSEs between ENOI_HadInit and NoInit (a), between SODAInit and NoInit (c), and between EnOI_HadInit and SODAInit for the forecast years 2-5. Hatched area identifies the region where the ratio is statistically significantly above or below 1 with $90 \%$ confidence level using a two-sided F-test.

of ocean state (NoInit). Meanwhile, the initialization with EnOI-assimilated data further improves the prediction skill of SST over the North Pacific Ocean, southern Indian Ocean, and the extratropics of the North Atlantic Ocean.

\subsection{SST indices}

Based on the map of significant ACC of SST predicted by EnOI_HadInit, four domains are selected to make further analysis of prediction skill over the forecast time. The chosen regions and their SST indices are: (i) the tropical western Pacific $\left(125-150^{\circ} \mathrm{E}\right.$, $15^{\circ} \mathrm{S}-15^{\circ} \mathrm{N}$ ), its SST index is denoted by the area averaged SST anomalies (TWP index); (ii) the North Pacific region $\left(180-210^{\circ} \mathrm{E}, 30-50^{\circ} \mathrm{N}\right)$, SST index is the area averaged SST anomalies (NP index); (iii) the southern Indian Ocean Dipole (SIOD) index, defined as the difference of SST anomalies averaged over $\left(45-75^{\circ} \mathrm{E}, 45-30^{\circ} \mathrm{S}\right)$ and $\left(80-100^{\circ} \mathrm{E}, 25-15^{\circ} \mathrm{S}\right)$; and (iv) the North Atlantic sector, denoted by AMO index, 

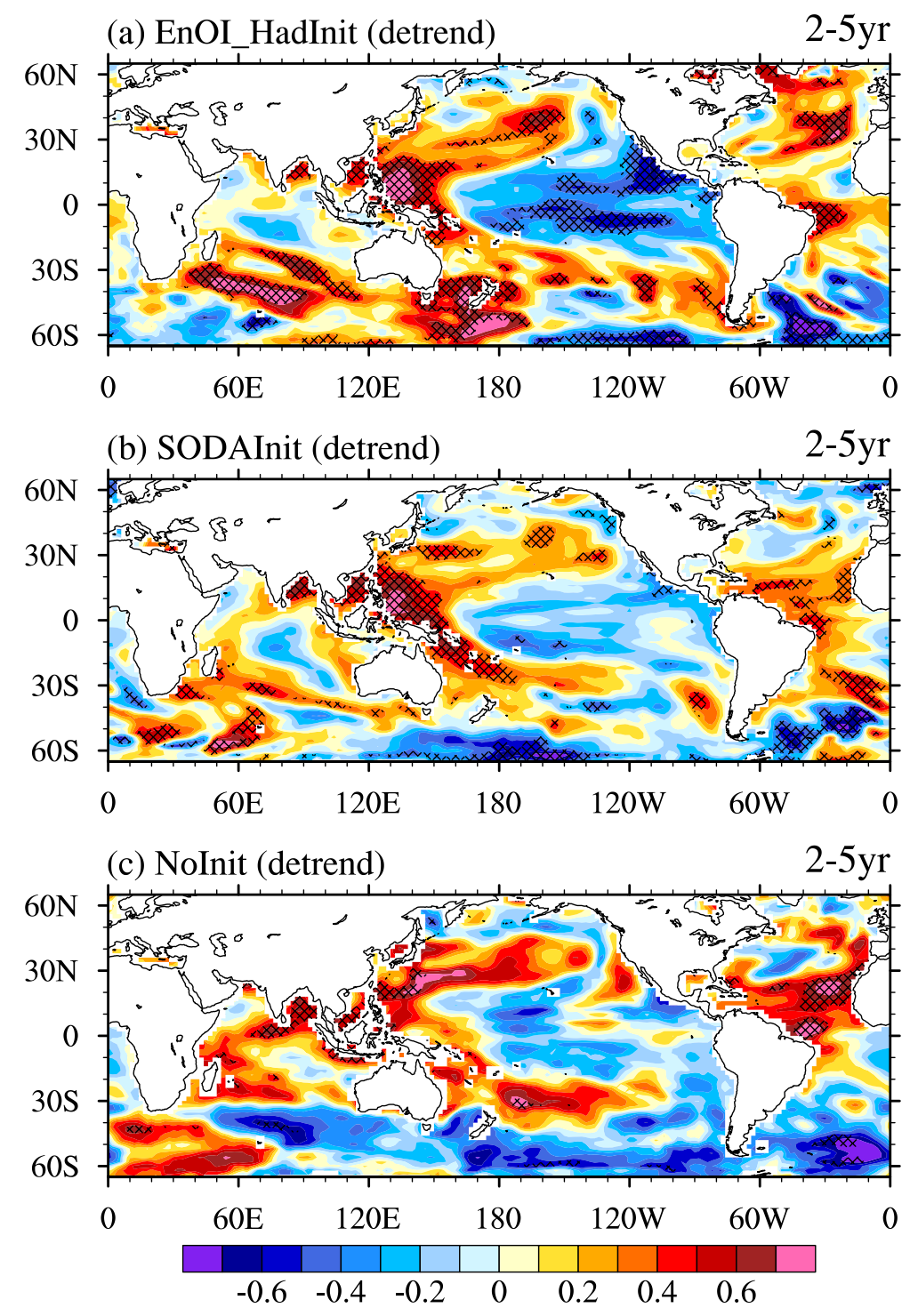

Fig. 3. ACC skills of SST hindcast by EnOI_HadInit (a), SODAInit (b), and NoInit (c) for the forecast years 2-5 with respect to the observation. Hatched area identifies the region where the ACC is above the $90 \%$ confidence level.

which is the SST anomalies in the North Atlantic $\left(80-0^{\circ} \mathrm{W}, 0-60^{\circ} \mathrm{N}\right)$ relative to the global-mean SST $\left(60^{\circ} \mathrm{S}-60^{\circ} \mathrm{N}\right)$.

ACCs of the SST indices between the hindcasts and the observed values are calculated in these four regions at different forecast time periods $(1-4,2-5$, $3-6,4-7,5-8,6-9)$. Figure $4 \mathrm{a}$ shows that both EnOI_HadInit and SODAInit have significant ACCs for TWP SST index over all forecast time periods from 1-4 to 6-9; but the former displays the relatively higher prediction skills in the forecast years of 1-4 and $2-5$.

Figure $4 \mathrm{~b}$ shows that over the North Pacific region, the ACCs of NP index from the EnOI HadInit are much higher than the ACCs from the SODAInit, and the former pass the $10 \%$ significant level while the latter do not for all forecast time periods. Furthermore, the ACC values of SIOD exceed 0.4 over all forecast time periods from 1-4 to 6-9 in EnOI_HadInit hindcast, which is much higher than the SODAInit and NoInit equivalents (Fig. 4c). The improved forecast skill up to 9-year ahead over the Indian Ocean by 

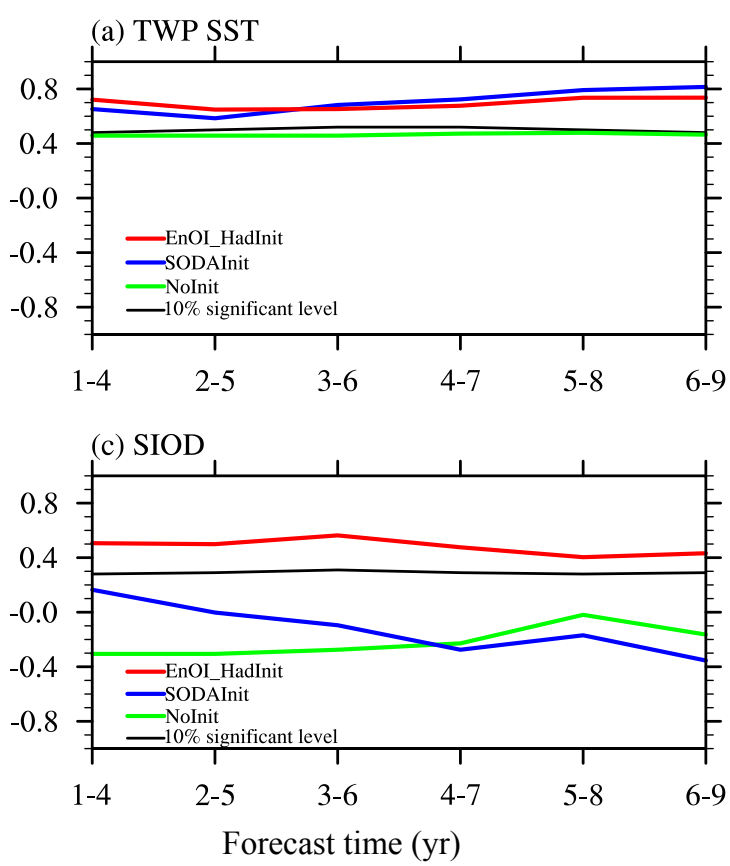
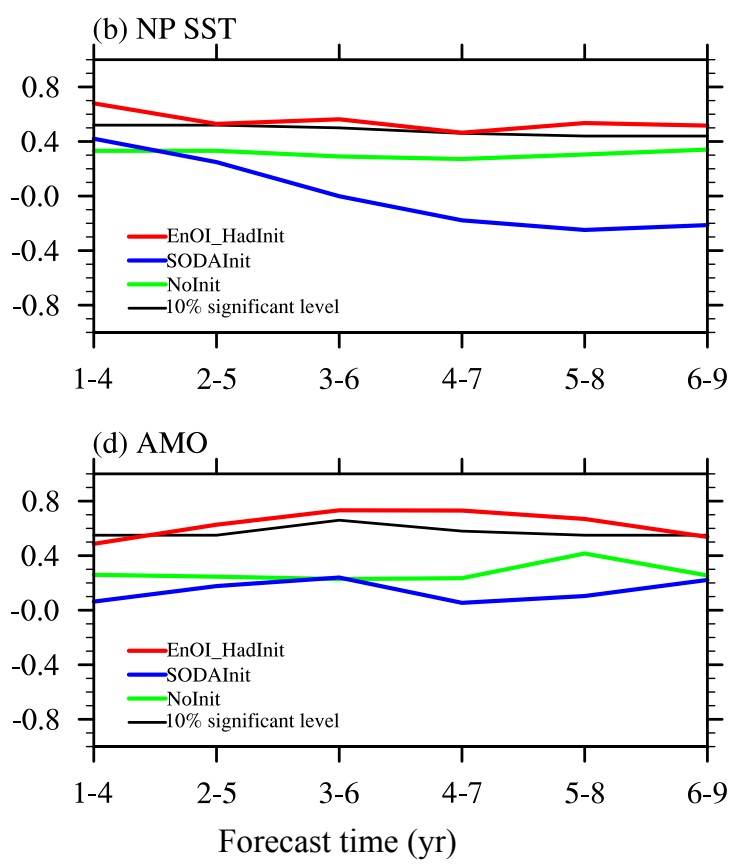

Fig. 4. ACCs between the hindcasts and the observation for TWP SST (a), NP SST (b), SIOD (c), and AMO (d) indices along the forecast time for 4-year averages.

EnOI HadInit is consistent with the simulation result from GEOS-5 model, in which the EnOI initialization scheme was also adapted (Ham et al. 2014).

Figure $4 \mathrm{~d}$ shows that the AMO can be well predicted by EnOI_HadInit for forecast time periods ranging from 2-5 up to 6-9 years, with ACC above the $10 \%$ significance level. However, the ACCs of AMO predicted by SODAInit and NoInit are much lower than those from EnOI_HadInit. The better prediction skill for AMO is consistent with the more skillful prediction of Atlantic meridional overturning circulation by EnOI_HadInit, which is documented by Wei et al. (2017).

It is concluded that using assimilated ocean data in the initialization improves the prediction skill for North Pacific SST, the SIOD, and AMO up to 6-9 years ahead for BCC-CSM1.1. The improved skill for some of these SST indices was reported in previous studies (Wu and Zhou 2012; Doblas-Reyes et al. 2013; Ham et al. 2014).

\section{Prediction skill of SAT}

\subsection{Surface air temperature}

The prediction skill of SAT over the land is explored. Figure 5 shows the ACCs beteen the hindcasts and the observed SAT for the forecast years
2-5, as well as the difference between them. Southern Europe and North Africa, East Asia, and Greenland stand out as the areas featuring high skills in the EnOI_HadInit hindcast (Fig. 5a). The prediction skill of EnOI_HadInit over southern Europe and Greenland is higher than that of SODAInit (Figs. 5b, c). EnOI_ HadInit and SODAInit are both skillful in predicting SAT over East Asia (Figs. 5a, b).

Figure 6 shows the area averaged SAT time series predicted by the decadal hindcasts for the forecast years $2-5$ over the selected regions, including South Europe and North Africa $\left(10-50^{\circ} \mathrm{E}, 15-55^{\circ} \mathrm{N}\right)$, East Asia $\left(100-120^{\circ} \mathrm{E}, 25-40^{\circ} \mathrm{N}\right)$, and Greenland $(300-$ $\left.340^{\circ} \mathrm{E}, \quad 60-80^{\circ} \mathrm{N}\right)$. The higher coefficient $(0.55)$ between the predicted SAT by EnOI_HadInit and observed SAT in the south Europe and North Africa indicates that EnOI_HadInit is able to predict more realistic SATs in these two regions than SODAInit (Fig. 6a). The time evolution of East Asian SAT predicted by EnOI_HadInit is similar with SODAInit, with the same ACC value 0.41 (Fig. 6b). Over Greenland, the predicted SAT by EnOI_HadInit is more consistent with the observation than SODAInit and NoInit (Fig. $6 c)$. 
(a) EnOI_HadInit

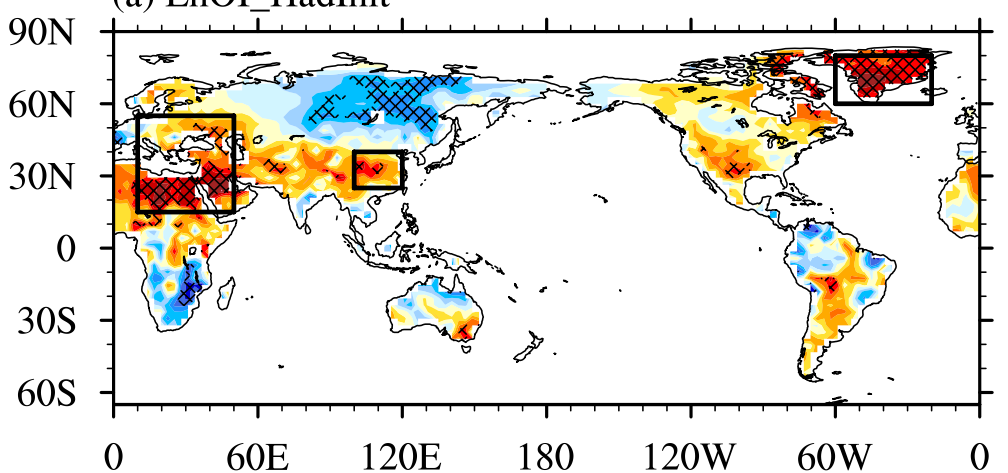

(b) SODAInit

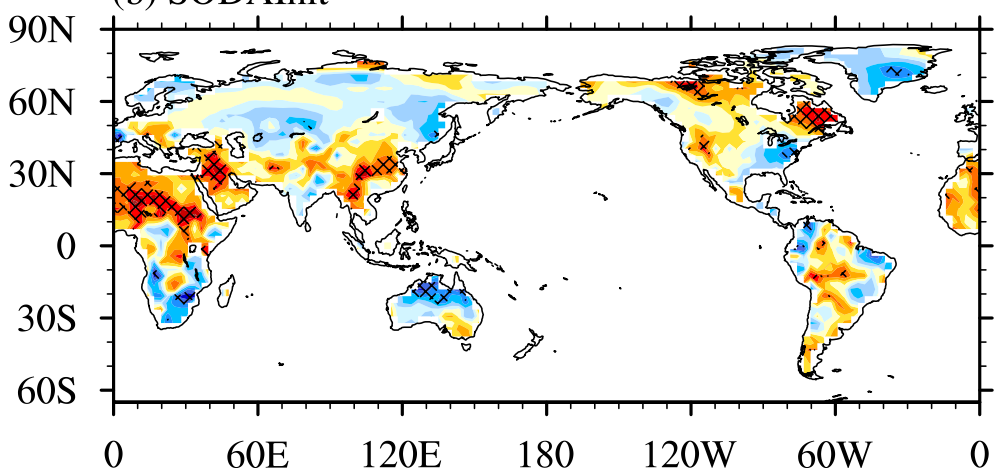

(c) EnOI_HadInit - SODAInit

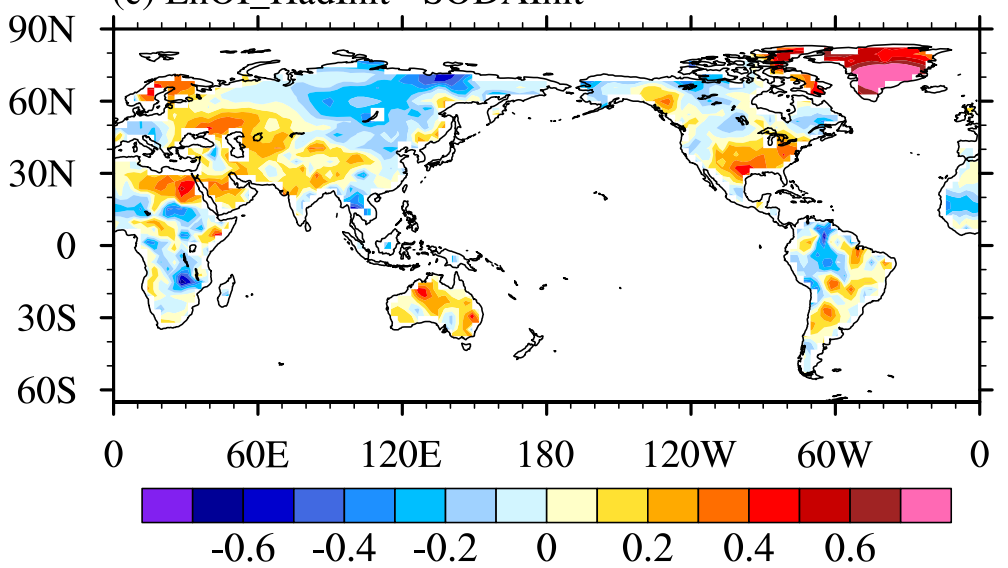

Fig. 5. ACC skills of SAT hindcast by EnOI_HadInit (a), SODAInit (b), and the difference between them (c) for the forecast years 2-5. Hatched area identifies the region where the ACC is above the $90 \%$ confidence level.

\subsection{Relationship between AMO and SAT}

The AMO was found to influence the climate of the surrounding continents (Knight et al. 2006). The skillful prediction of the AMO has the potential impacts on the prediction skill of regional climate. We attempted to further investigate where the prediction skill of SAT is related to the AMO in the decadal hindcasts with

\section{BCC-CSM1.1.}

As shown in Fig. 7a, the predicted SAT by EnOI HadInit is closely correlated to the AMO index over South Europe and North Africa and Greenland. This is consistent with the observation (Fig. 7c). Therefore, we argue that the higher prediction skills of EnOI HadInit in these three regions are related to its skillful 
(a) South Europe and North Africa

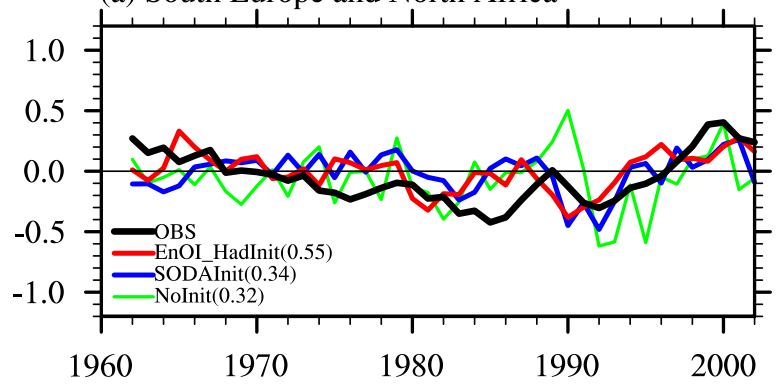

(b) East Asia

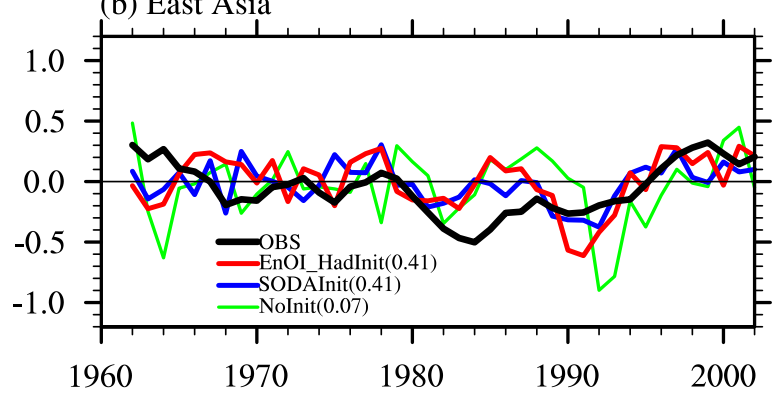

(c) Greenland

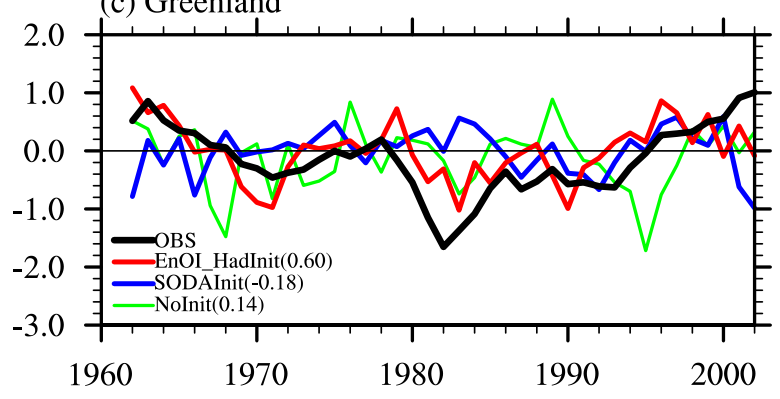

Fig. 6. Time series of SAT averaged over Europe and North Africa (a), East Asia (b), and Greenland (c) in decadal hindcasts for the forecast years $2-5$. The value in the bracket indicates correlation coefficient between the hindcast and observation.

prediction in the AMO. It is noted that the SODAInit also reproduces the robust correlation between the AMO and the SAT in Greenland. However, SODAInit has poor skill in the hindcast of the AMO (Fig. 7b). This may explain why there is little ACC skill for the Greenland SAT in SODIAInit (Figs. 5c, 6c).

\subsection{Relationship between East Asian SAT and SST indices}

The observed East Asian climate is influenced by the Pacific SST and the AMO (Zhou et al. 2008; Si and Ding 2016). Since East Asian SAT could be well predicted by both EnOI_HadInit and SODAInit, we expect to explore its relationship with these SST indices in the decadal hindcasts for the forecast years $2-5$.

As shown in Table 2, the observed East Asian SAT is positively correlated with the TWP, NP, and AMO indices significantly, and negatively correlated with SIOD index significantly. EnOI HadInit and SODAInit both reproduce the significant positive correlation between East Asian SAT and TWP SST, although they both overestimate the correlation coefficients. The atmospheric process linking the TWP SST with the East Asian SAT in the SODAInit prediction was revealed by Xin et al. (2018).

The relationship between East Asian SAT and other SST indices including NP, SIOD and AMO indices could not be reproduced by EnOI_HadInit and SODAInit hindcasts. So it is inferred that the prediction skill of East Asian SAT mainly arises from the oceanic forcing from the TWP in EnOI HadInit and SODAInit hindcasts. The physical processes linking East Asian climate with SST in the North Pacific, SIOD, and the AMO need further improvement in climate models. This will favor further improvement in the forecast skill over East Asia in decadal predictions.

\section{Conclusions}

We assessed and compared the prediction skills of two sets of decadal prediction experiments (SODAInit and EnOI HadInit) carried out with BCC-CSM1.1. SODAInit and EnOI HadInit differ in the ocean initialization scheme and the observed sea temperature data used in the initialization. SODAInit used the SODA reanalysis data, while the EnOI_HadInit used the assimilated ocean data generated by assimilating HadISST to the ocean model of BCC-CSM1.1 using the EnOI method. We found that EnOI_HadInit is more skillful in predicting the SST over the North Pacific, the North Atlantic, and southern Indian Ocean than SODAInit. The SIOD and AMO indices are well predicted by EnOI_HadInit over forecast time periods ranging from 2-5 up to 6-9 years.

The EnOI_HadInit has better prediction skills for SAT over South Europe, North Africa, and Greenland than the SODAInit, which is related to its skillful prediction of the AMO. In addition, EnOI_HadInit and SODAInit are both skillful in predicting the East Asian SAT. This is related to the skillful prediction of the TWP SST. The observed close relationship between East Asian SAT and North Pacific SST, SIOD, and AMO indices could not be reproduced by the decadal hindcasts and needs further improvement.

These increased skills in SST and SAT predicted 
(a) Cor(SAT,AMO), EnOI_HadInit

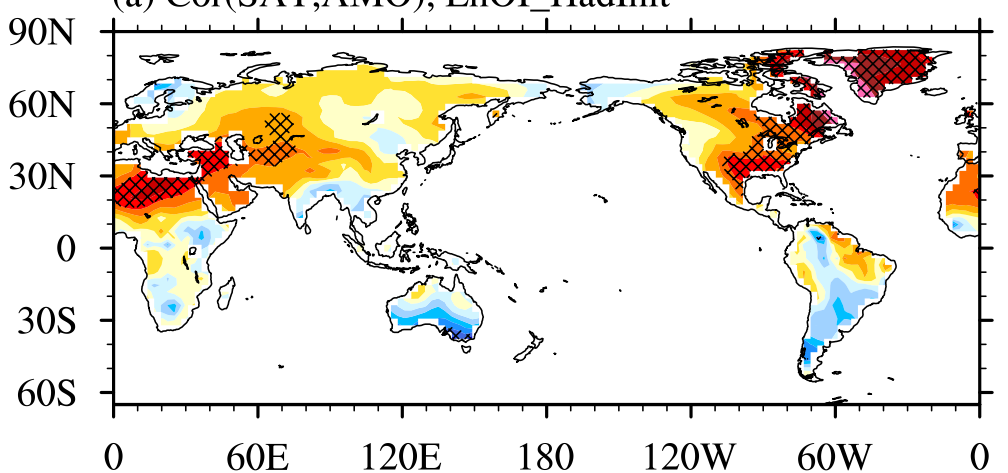

(b) Cor(SAT,AMO), SODAInit

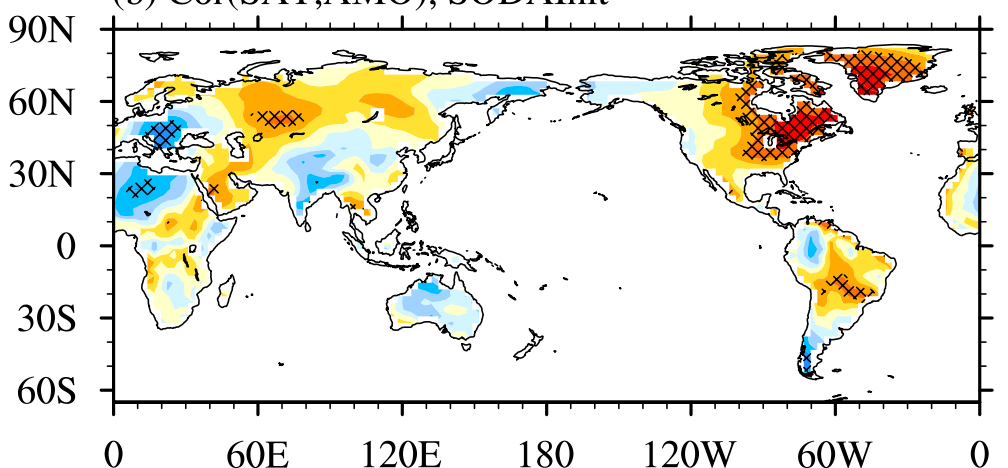

(c) Cor(SAT,AMO),OBS

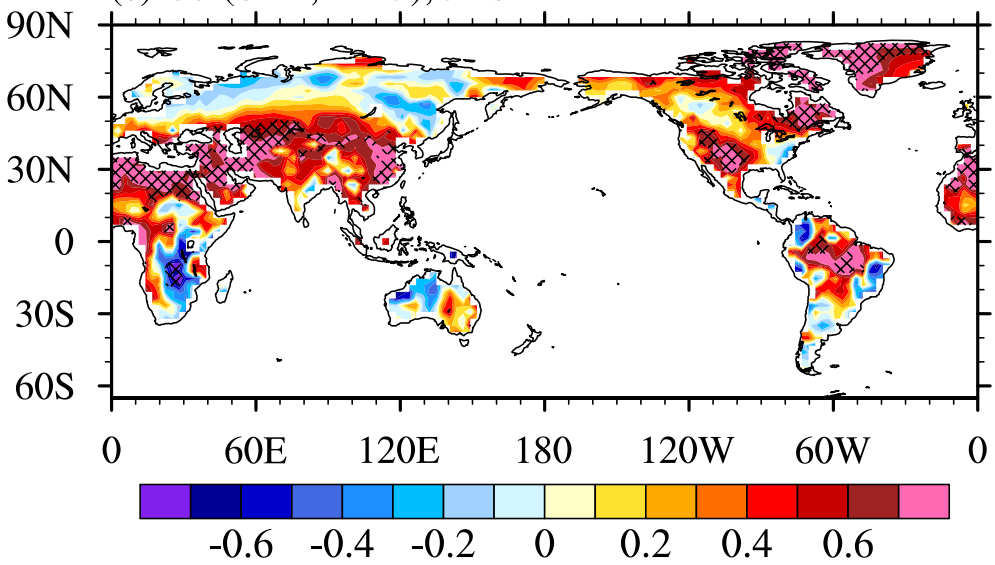

Fig. 7. Correlation between SAT and AMO index hindcast by EnOI_HadInit (a), SODAInit (b), and observation (c) for the forecast years 2-5. Hatched area identifies the region where the ACC is above the $90 \%$ confidence level.

by EnOI_HadInit confirm that the assimilated data generated by the ocean model of BCC-CSM1.1 with EnOI assimilation can provide better initial conditions than SODA reanalysis data for the decadal predictions of BCC-CSM1.1. It indicates that appropriately constraining the initial states of the model through assimilation strategy is crucial for decadal predictions.
Wu et al. (2018) constructed a decadal prediction system with EnOI and incremental analysis update scheme, which was verified to be skillful in the prediction of SST anomalies in midlatitude North Pacific, North Atlantic, and the key areas of ENSO. Further development based on EnOI needs to be done in the decadal prediction systems of BCC-CSM. The assim- 
Table 2. Correlation coefficients between East Asian (100$\left.120^{\circ} \mathrm{E}, 25-40^{\circ} \mathrm{N}\right)$ SAT time series with tropical western Pacific (TWP) SST, North Pacific (NP) SST, southern Indian Ocean Dipole (SIOD), and Atlantic multi-decadal oscillation (AMO) indices hindcast by EnOI_HadInit and SODAInit for the forecast years $2-5$, as well as in the observation. All data are detrended before the calculation. Bold values are above the $90 \%$ confidence level.

\begin{tabular}{lcccc}
\hline Experiment name & TWP SST & NP SST & SIOD & AMO \\
\hline EnOI_HadInit & $\mathbf{0 . 7 2}$ & 0.33 & -0.15 & 0.14 \\
SODAInit & $\mathbf{0 . 6 1}$ & 0.37 & -0.25 & 0.02 \\
OBS & $\mathbf{0 . 4 1}$ & $\mathbf{0 . 5 6}$ & $\mathbf{- 0 . 4 2}$ & $\mathbf{0 . 7 9}$ \\
\hline
\end{tabular}

ilation of the ocean salinity will also be considered in the new decadal prediction systems of BCC-CSM.

\section{Acknowledgments}

This work was jointly supported by the National Program on Key Basic Research Project of China (2016YFA0602100, 2016YFA0602200, 2016YFE 0102404, 2012CB955203, and 2013CB430202), and Tsinghua University Initiative Scientific Research Program (20131089357).

\section{References}

Bellucci, A., S. Gualdi, S. Masina, A. Storto, E. Scoccimarro, C. Cagnazzo, P. Fogli, E. Manzini, and A. Navarra, 2013: Decadal climate predictions with a coupled OAGCM initialized with oceanic reanalyses. Climate Dyn., 40, 1483-1497.

Boer, G. J., D. M. Smith, C. Cassou, F. Doblas-Reyes, G. Danabasoglu, B. Kirtman, Y. Kushnir, M. Kimoto, G. A. Meehl, R. Msadek, W. A. Mueller, K. E. Taylor, F. Zwiers, M. Rixen, Y. Ruprich-Robert, and R. Eade, 2016: The Decadal Climate Prediction Project (DCPP) contribution to CMIP6. Geosci. Model. Dev., 9, 3751-3777.

Bretherton, C. S., M. Widmann, V. P. Dymnikov, J. M. Wallace, and I. Bladé, 1999: The effective number of spatial degrees of freedom of a time-varying field. $J$. Climate, 12, 1990-2009.

Carton, J. A., and B. S. Giese, 2008: A reanalysis of ocean climate using Simple Ocean Data Assimilation (SODA). Mon. Wea. Rev., 136, 2999-3017.

Doblas-Reyes, F. J., I. Andreu-Burillo, Y. Chikamoto, J. García-Serrano, V. Guemas, M. Kimoto, T. Mochizuki, L. R. L. Rodrigues, and G. J. van Oldenborgh, 2013: Initialized near-term regional climate change prediction. Nat. Commun., 4, 1715, doi:10.1038/ncomms 2704.

Eyring, V., S. Bony, G. A. Meehl, C. A. Senior, B. Stevens, R. J. Stouffer, and K. E. Taylor, 2016: Overview of the Coupled Model Intercomparison Project Phase
6 (CMIP6) experimental design and organization. Geosci. Model. Dev., 9, 1937-1958.

Fan, Y., and H. van den Dool, 2008: A global monthly land surface air temperature analysis for 1948-present. $J$. Geophys. Res., 113, D01103, doi: 10.1029/2007JD 008470 .

Gaetani, M., and E. Mohino, 2013: Decadal prediction of the Sahelian precipitation in CMIP5 simulation. $J$. Climate, 26, 7708-7719.

Gao, F., X. Xin, and T. Wu, 2012: A study of the prediction of regional and global temperature on decadal time scale with BCC_CSM1.1 model. Chinese J. Atmos. Sci., 36, 1165-1179 (in Chinese with English abstract).

García-Serrano, J., and F. J. Doblas-Reyes, 2012: On the assessment of near-surface global temperature and North Atlantic multi-decadal variability in the ENSEMBLES decadal hindcast. Climate Dyn., 39, 2025-2040.

Goddard, L., A. Kumar, A. Solomon, D. Smith, G. Boer, P. Gonzalez, V. Kharin, W. Merryfield, C. Deser, S. J. Mason, B. P. Kirtman, R. Msadek, R. Sutton, E. Hawkins, T. Fricker, G. Hegerl, C. A. T. Ferro, D. B. Stephenson, G. A. Meehl, T. Stockdale, R. Burgman, A. M. Greene, Y. Kushnir, M. Newman, J. Carton, I. Fukumori, and T. Delworth, 2012: A verification framework for interannual-to-decadal predictions experiments. Climate Dyn., 40, 245-272.

Griffies, S. M., A. Gnanadesikan, K. W. Dixon, J. P. Dunne, R. Gerdes, M. J. Harrison, A. Rosati, J. L. Russell, B. L. Samuels, M. J. Spelman, M. Winton, and R. Zhang, 2005: Formulation of an ocean model for global climate simulations. Ocean Sci., 1, 45-79.

Ham, Y.-G., M. M. Rienecker, M. J. Suarez, Y. Vikhliaev, B. Zhao, J. Marshak, G. Vernieres, and S. D. Schubert, 2014: Decadal prediction skill in the GEOS-5 forecast system. Climate Dyn., 42, 1-20.

Han, Z. Y., B. Wu, and X. G. Xin, 2017: Decadal prediction skill of the global sea surface temperature in the BCCCSM1.1 climate model. Adv. Earth Sci., 32, 382-395 (in Chinese with English abstract).

Huang, B., P. W. Thorne, T. M. Smith, W. Liu, J. Lawrimore, V. F. Banzon, H.-M. Zhang, T. C. Peterson, and M. Menne, 2016: Further exploring and quantifying uncertainties for Extended Reconstructed Sea Surface Temperature (ERSST) version 4 (v4). J. Climate, 29, 3119-3142.

IPCC, 2013: Climate Change 2013: The Physical Science Basis. Contribution of Working Group I to the Fifth Assessment Report of the Intergovernmental Panel on Climate Change. Stocker, T. F., D. Qin, G.-K. Plattner, M. M. B. Tignor, S. K. Allen, J. Boschung, A. Nauels, Y. Xia, V. Bex, and P. M. Midgley (eds.), Cambridge University Press, $1523 \mathrm{pp}$.

Kalnay, E., M. Kanamitsu, R. Kistler, W. Collins, D. Deaven, L. Gandin, M. Iredell, S. Saha, G. White, J. Woollen, Y. Zhu, M. Chelliah, W. Ebisuzaki, W. 
Higgins, J. Janowiak, K. C. Mo, C. Ropelewski, J. Wang, A. Leetmaa, R. Reynolds, R. Jenne, and D. Joseph, 1996: The NCEP/NCAR 40-Year Reanalysis Project. Bull. Amer. Meteor. Soc., 77, 437-470.

Keenlyside, N. S., M. Latif, J. Jungclaus, L. Kornblueh, and E. Roeckner, 2008: Advancing decadal-scale climate prediction in the North Atlantic sector. Nature, 453, 84-88.

Kim, H.-M., P. J. Webster, and J. A. Curry, 2012: Evaluation of short-term climate change prediction in multi-model CMIP5 decadal hindcasts. Geophys. Res. Lett., 39, L10701, doi:10.1029/2012GL051644.

Knight, J. R., C. K. Folland, and A. A. Scaife, 2006: Climate impacts of the Atlantic Multidecadal Oscillation. Geophys. Res. Lett., 33, L17706, doi:10.1029/2006GL 026242.

Li, Q.-Q., J. Tan, L.-N. Wang, M. Wei, and Q.-G. Zhao, 2015: Simulation of the natural distribution of carbon and nutrients in the ocean based on the global ocean carbon cycle model MOM4_L40. Chinese J. Geophys., 58, 1-19.

Meehl, G. A., L. Goddard, G. Boer, R. Burgman, G. Branstator, C. Cassou, S. Corti, G. Danabasoglu, F. DoblasReyes, E. Hawkins, A. Karspeck, M. Kimoto, A. Kumar, D. Matei, J. Mignot, R. Msadek, A. Navarra, H. Pohlmann, M. Rienecker, T. Rosati, E. Schneider, D. Smith, R. Sutton, H. Teng, G. J. van Oldenborgh, G. Vecchi, and S. Yeager, 2014: Decadal climate prediction: An update from the trenches. Bull. Amer. Meteor. Soc., 95, 243-267.

Rayner, N. A., D. E. Parker, E. B. Horton, C. K. Folland, L. V. Alexander, D. P. Rowell, E. C. Kent, and A. Kaplan, 2003: Global analyses of sea surface temperature, sea ice, and night marine air temperature since the late nineteenth century. J. Geophys. Res., 108, 4407, doi:10.1029/2002JD002670.

Si, D., and Y. H. Ding, 2016: Oceanic forcings of the interdecadal variability in East Asian summer rainfall. $J$. Climate, 29, 7633-7649.

Smith, D. M., S. Cusack, A. W. Colman, C. K. Folland, G. R. Harris, and J. M. Murphy, 2007: Improved surface temperature prediction for the coming decade from a global climate model. Science, 317, 796-799.

Taylor, K. E., R. J. Stouffer, and G. A. Meehl, 2012: An overview of CMIP5 and the experiment design. Bull. Amer. Meteor. Soc., 93, 485-498.
University of East Anglia Climatic Research Unit, I. Harris, and P. D. Jones, 2015: CRU TS3.23: Climatic Research Unit (CRU) Time-Series (TS) Version 3.23 of High Resolution Gridded Data of Month-by-month Variation in Climate (Jan. 1901-Dec. 2014). Centre for Environmental Data Analysis, 09 November 2015, doi:10.5285/4c7fdfa6-f176-4c58-acee-683d5e9d2ed5.

Wei, M., Q. Li, X. Xin, W. Zhou, Z. Han, Y. Luo, and Z. Zhao, 2017: Improved decadal climate prediction in the North Atlantic using EnOI-assimilated initial condition. Sci. Bull., 62, 1142-1147.

Wu, B., and T. J. Zhou, 2012: Prediction of decadal variability of sea surface temperature by a coupled global climate model FGOALS_gl developed in LASG/IAP. Chinese Sci. Bull., 57, 2453-2459.

Wu, B., X. Chen, F. Song, Y. Sun, and T. Zhou, 2015: Initialized decadal predictions by LASG/IAP climate system model FGOALS-s2: Evaluations of strengths and weaknesses. Adv. Meteor, 6, 904826, doi:10.1155/ 2015/904826.

Wu, B., T. Zhou, and F. Zheng, 2018: EnOI-IAU initialization scheme designed for decadal climate prediction system IAP-DecPreS. J. Adv. Model. Earth Syst., 10, 342-356.

Wu, T., R. Yu, F. Zhang, Z. Wang, M. Dong, L. Wang, X. Jin, D. Chen, and L. Li, 2010: The Beijing Climate Center for atmospheric general circulation model: Description and its performance for the present-day climate. Climate Dyn., 34, 123-147.

Wu, T., W. Li, J. Ji, X. Xin, L. Li, Z. Wang, Y. Zhang, J. Li, F. Zhang, M. Wei, X. Shi, F. Wu, L. Zhang, M. Chu, W. Jie, Y. Liu, F. Wang, X. Liu, Q. Li, M. Dong, X. Liang, Y. Gao, and J. Zhang, 2013: Global carbon budgets simulated by the Beijing Climate Center Climate System Model for the last century. J. Geophys. Res., 118, 4326-4347.

Xin, X., F. Gao, M. Wei, T. Wu, Y. Fang, and J. Zhang, 2018: Decadal prediction skill of BCC-CSM1.1 model in East Asia. Int. J. Climatol., 38, 584-592.

Xin, X.-G., T.-W. Wu, and J. Zhang, 2013: Introduction of CMIP5 experiments carried out with the climate system models of Beijing Climate Center. Adv. Climate Change Res., 4, 41-49.

Zhou, T., R. Yu, H. Li, and B. Wang, 2008: Ocean forcing to changes in global monsoon precipitation over the recent half-century. J. Climate, 21, 3833-3852. 